\title{
Study of Storage Shelves Deformation Using Finite Element Analysis during Seismic
}

\author{
Dyi-Cheng Chen ${ }^{1, a}$ and Tsung-Ying Kuo ${ }^{1}$ \\ ${ }^{1}$ Department of Industrial Education and Technology, National Changhua University of Education, Changhua 500, \\ Taiwan
}

\begin{abstract}
In recent years the government strongly promoted industry 4.0. Domestic enterprises highly developed of wisdom manufactured. Therefore, in the warehouse, the automatic storage system has gradually been taken seriously. The focus of this study is on the deformation of the shelves during the earthquake. First, this study used Inventor graphics software to model the shelf, the model into the Workbench for meshing and conditional constraints, then the completion of the model into ANSYS waiting for the solution. In earthquake conditions, in this study a scale 6-level seismic data is taken from the network PEER seismic database system. Using the ANSeismic program developed in Matlab, the seismic data downloaded from the network is transformed into ANSYS readable seismic code. The simulation results can be obtained by importing the seismic code into ANSYS and model simulation. In this study, we observed and analyzed the simulation results, through the shelf stress, strain and deformation to analyze the situation of the shelves, and improved the shelf structure.
\end{abstract}

\section{Introduction}

In recent years the government strongly promoted the industry 4.0. It is domestic enterprises a high degree of development of wisdom, with the application of new technologies such as internet of things, automatic warehousing, storage robots, mechanical vision and robotic arms. Industrial automation logistics system also will be produced. Which automatic storage system as part of the advanced manufacturing system [1]. Because of the easy operation, rapid processing, saving manpower and footprint and other advantages have gradually become a variety of industry management warehouse alternative [2].

Taiwan is located in the Pacific Rim seismic belt. The island has the frequency of frequent earthquakes. From the previous experience of the earthquake found domestic enterprises to be caused production disruption during the earthquake, mainly due to the destruction of production equipment [3]. The main body of the shelves is made of cold plates. Use bolts to assemble columns, beams and other parts, when the shelf by the role of goods, its structure of the external force and internal force to maintain a balance. The balance of the shelf is divided into the lasting balance state and limit balance state, when in the limit equilibrium state. As long as the application of an external force to balance the state, its structure will be destroyed and collapsed [4].

\footnotetext{
${ }^{\mathrm{a}}$ Corresponding author : dcchen@cc.ncue.edu.tw
} 
Based on the above, this study hopes to use finite element analysis to simulate the deformation of the shelves in the 6 earthquake. Observe the simulation results improved the structural strength of the shelves, to reduce the loss of natural disasters for the industry.

\section{Methodology}

Finite element method (FEM) for an unknown continuum to be analyzed, its complexity is difficult to get the mathematical solution of the analysis. You can use finite element analysis. The analytical solution is obtained from the mathematical formula of the "partial", and the analysis results include an infinite number of "partial" components. The principle assumes that this continuum is divided into finite "partial", called the element, the element of the boundary point called the node. Each node carries a mathematical equation, called interpolation equation. The analytic behavior of the continuum is expressed by a finite interpolation function equation. As long as the parameters are assumed to be correct and within tolerance errors. The exact solution of the solution can be compared with the exact solution of this continuum [5].

\section{Establishment of Storage Shelves Finite Element Model and Condition Setting}

This study is based on the market commonly used iron plate cold bay assembly rack to model. Inventor3D graphics software built the model, as shown in Fig. 1. The shelves can put a total of 60 boxes, each box the highest load $50 \mathrm{~kg}$. In this study, the full storage rate of $80 \%$ of the load conditions. In the condition set, the shelf material is set to iron, Density of $7.9 \mathrm{~g} / \mathrm{cm}^{3}$, Elasticity coefficient is $\mathrm{E}=211 \mathrm{GPa}$, Poisson's ratio of 0.3 , and the $\mathrm{Y}$-axis vertical contact with the ground bottom of the shelf area as a fixed end. In the condition set with fixed constraints, as shown in Fig. 2 [6].

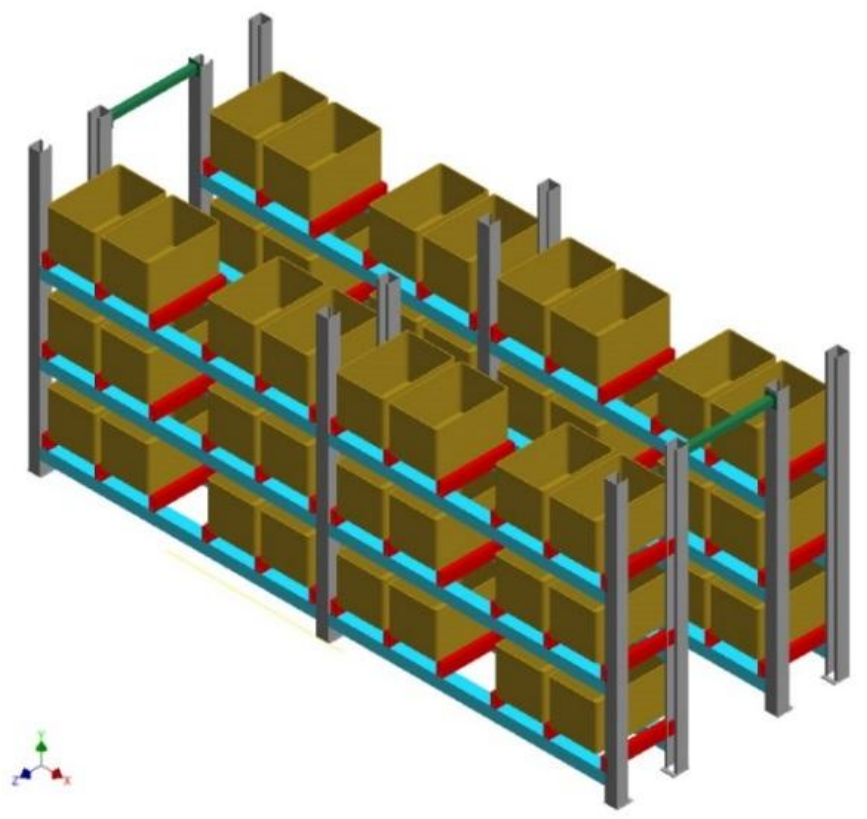

Figure 1. Storage shelves model 


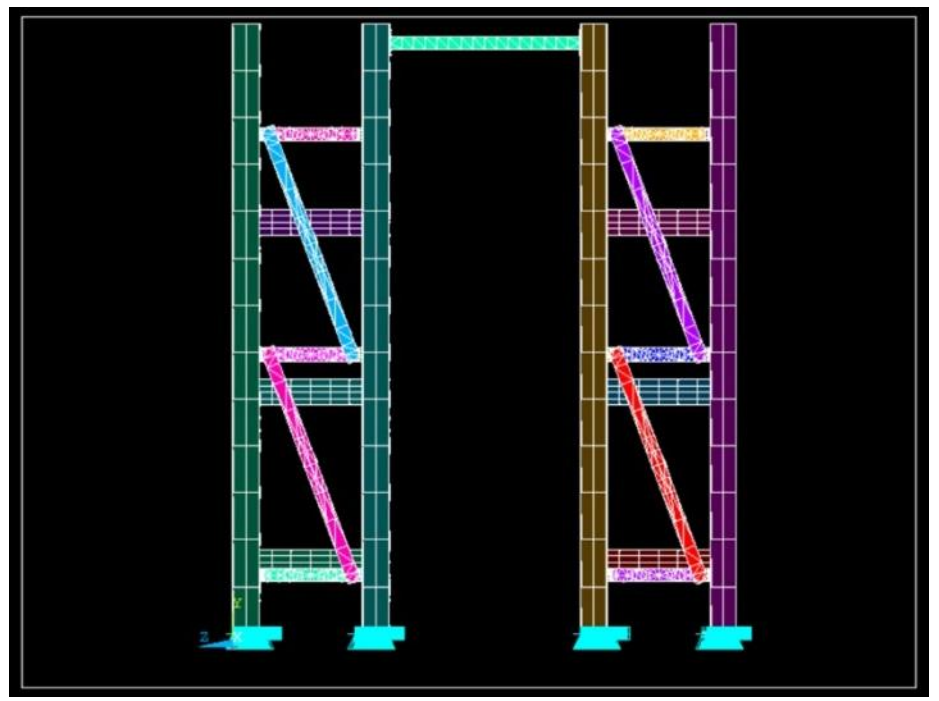

Figure 2. Model condition setting

\section{Seismic Numerical Application}

ANSeismic program is developed in Matlab. It can be in the PEER seismic database system to obtain real seismic data, and converted to ANSYS readable seismic code, to facilitate post-processing in ANSYS [7].

The quasi-simulated earthquake is a magnitude 6 earthquake, as shown in Fig. 3, the seismic data in the PEER seismic database system. This study needs the maximum value of $0.27516 \mathrm{~g}$, in the national 6 earthquake $0.25 \mathrm{~g} \sim 0.4 \mathrm{~g}$ within the definition.

Seismic waves are divided into transverse and longitudinal waves. Since the longitudinal wave propagation velocity is faster than the lateral wave, often the role of vertical seismic force on the shelves, the level of seismic power to reach. It can be considered that the longitudinal and lateral seismic forces are acting on the shelves, respectively [8]. The study is mainly to observe the shelves by the 6 level of seismic force when the deformation state.
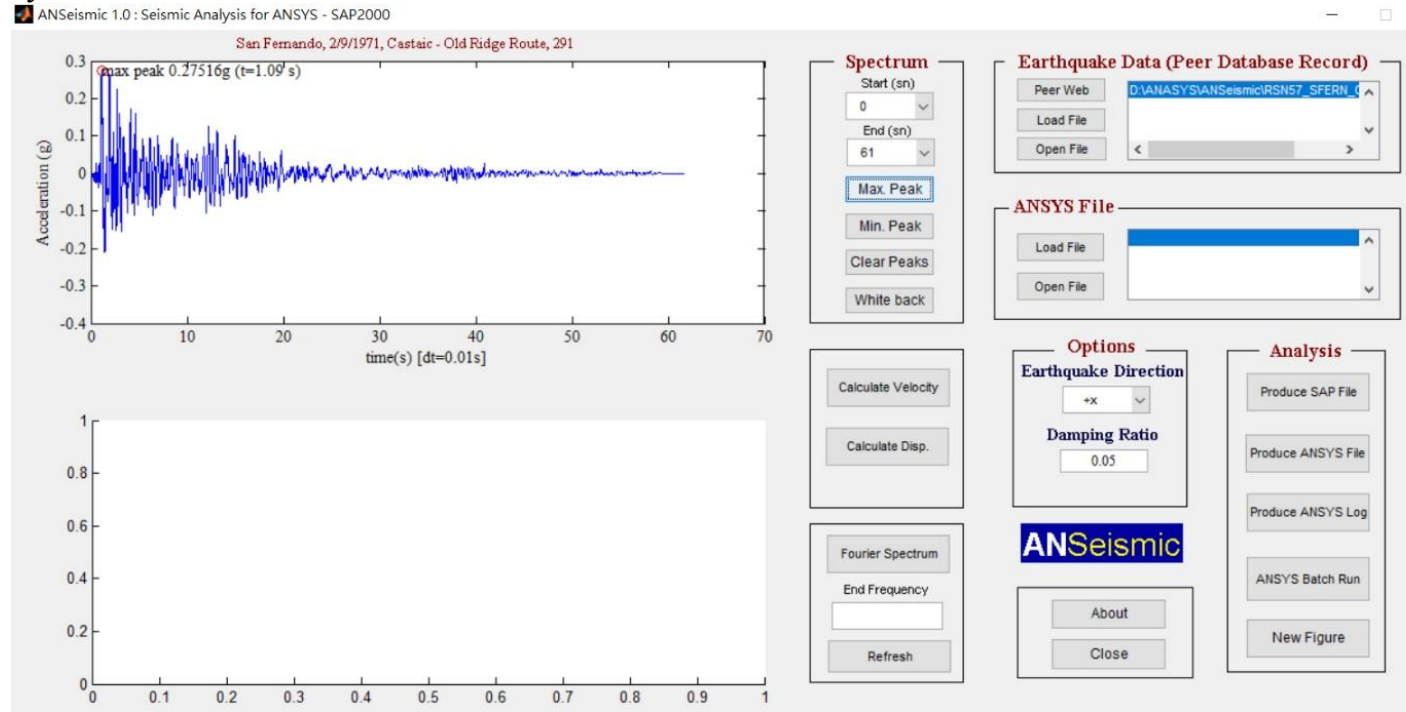

Figure 3. ANSeismic program main window 


\section{Analysis of Simulation Results}

As shown in Fig. 4, the shelves in the $\mathrm{X}$ axis 1.09 seconds when the earthquake simulation deformation diagram, observation of this Fig. 4 can be found, the deformation of the shelf increases with height, deformation also gradually increased. In the top of the head and tail position of the maximum deformation is $0.302 \mathrm{E}-04 \mathrm{~mm}$. The minimum amount of deformation at the bottom is zero.

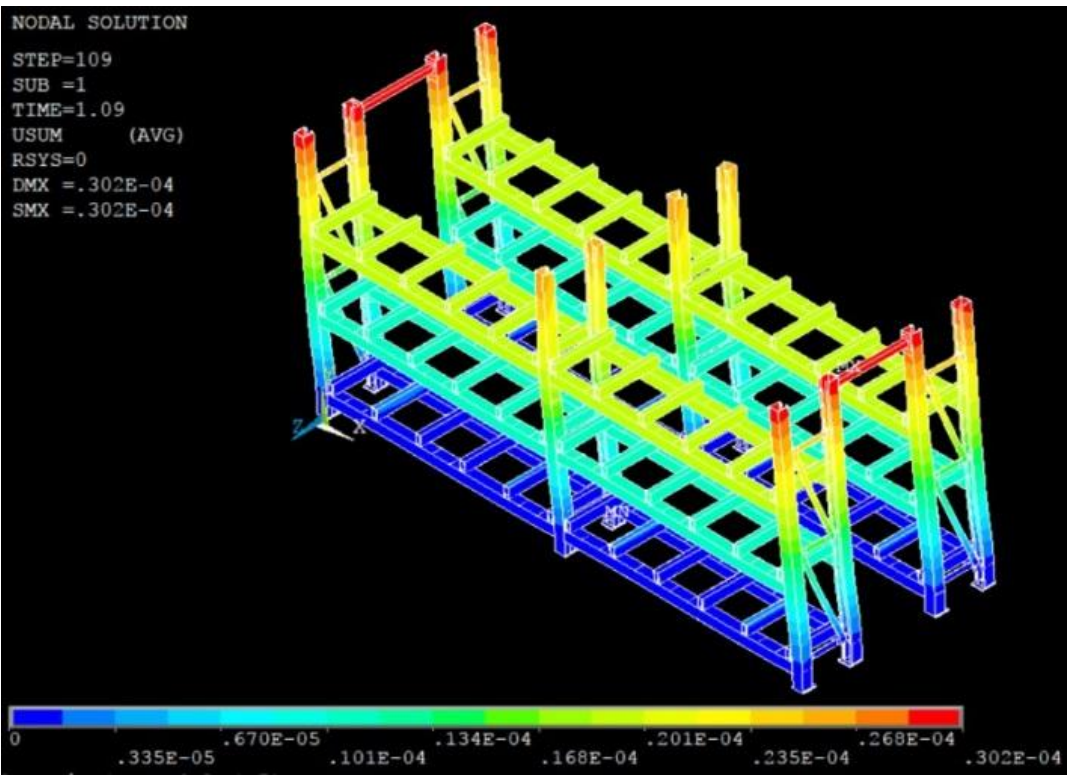

Figure 4. $\mathrm{X}$-axis storage shelves deformation

As shown in Fig. 5, the shelves in the Z-axis 1.09 seconds when the earthquake simulation deformation diagram, observation of this Fig. 5 can be found, the deformation of the shelf increases with height, deformation also gradually increased. And in the same height of the middle of the deformation of the shelves are greater than the head and tail of the deformation, the maximum value of $0.545 \mathrm{E}-04 \mathrm{~mm}$. The minimum amount of deformation at the bottom is zero.

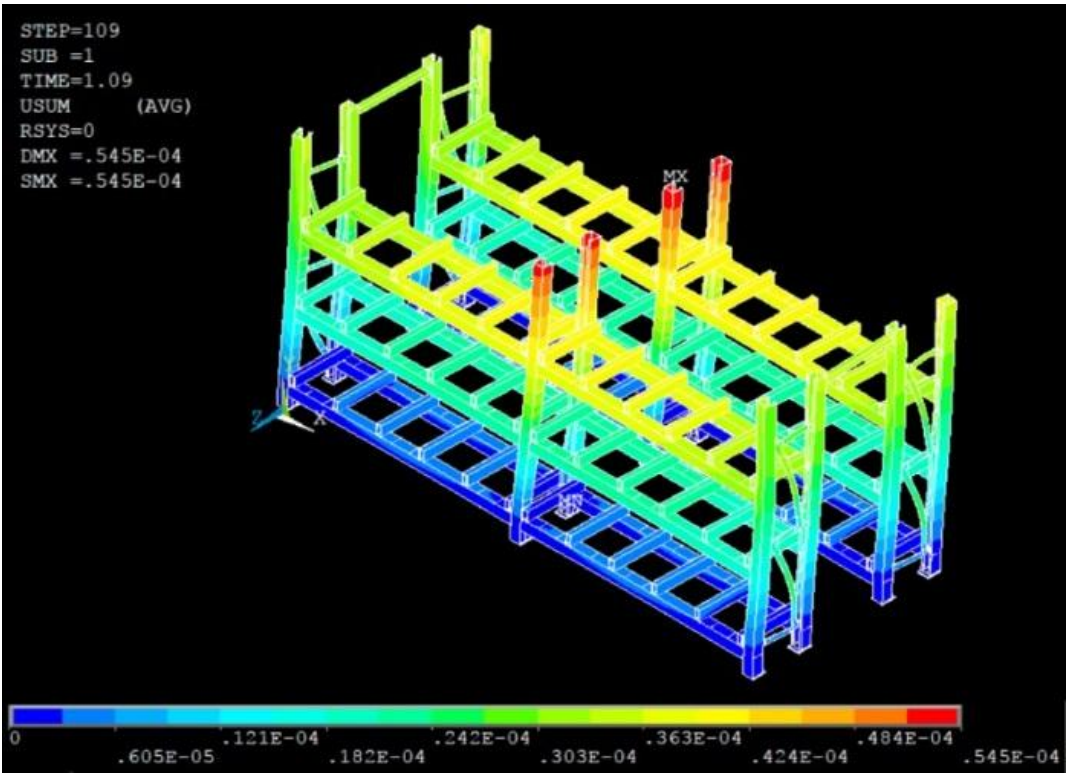

Figure 5. Z-axis storage shelves deformation 
As shown in Fig. 6, the shelves in the $\mathrm{X}$ axis 1.09 seconds when the seismic simulation of the strain diagram, observation of this Fig. 6 can be found, the shelf strain are concentrated in the columns, and the greater the bottom of the larger strain, the maximum value of $0.431 \mathrm{E}-05$, beam at the junction with the column at a higher strain value of $0.959 \mathrm{E}-06$. The minimum value of the overall shelf strain is $0.172 \mathrm{E}-08$.

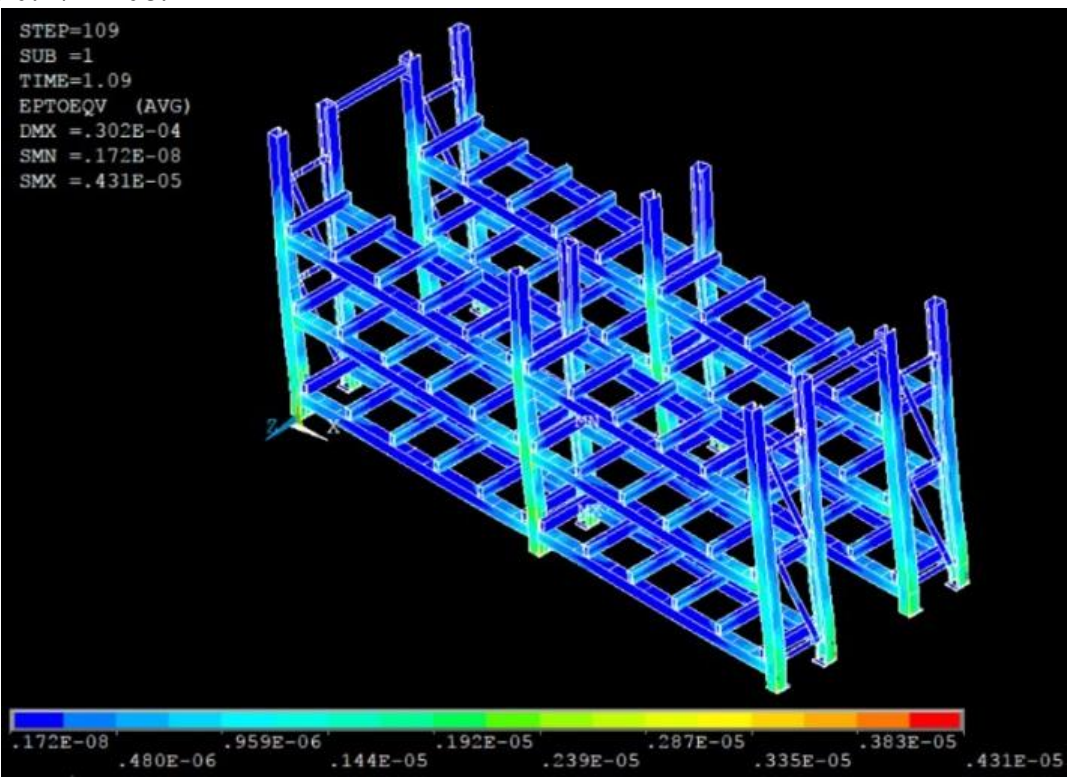

Figure 6. $\mathrm{X}$-axis storage shelves strain

As shown in Fig. 7, the shelves in the Z-axis 1.09 seconds when the seismic simulation of the strain diagram, observation of this Fig. 7 can be found, the shelf strain are concentrated in the columns, and the greater the bottom of the larger strain, the maximum value of $0.264 \mathrm{E}-04$. The strain value of the beam at the junction with the column is higher, 0.294E-05, Z-axis column between the rods also have strain occurred, the closer the bottom of the rod strain the greater the strain. The minimum value of the overall shelf strain is $0.562 \mathrm{E}-08$.

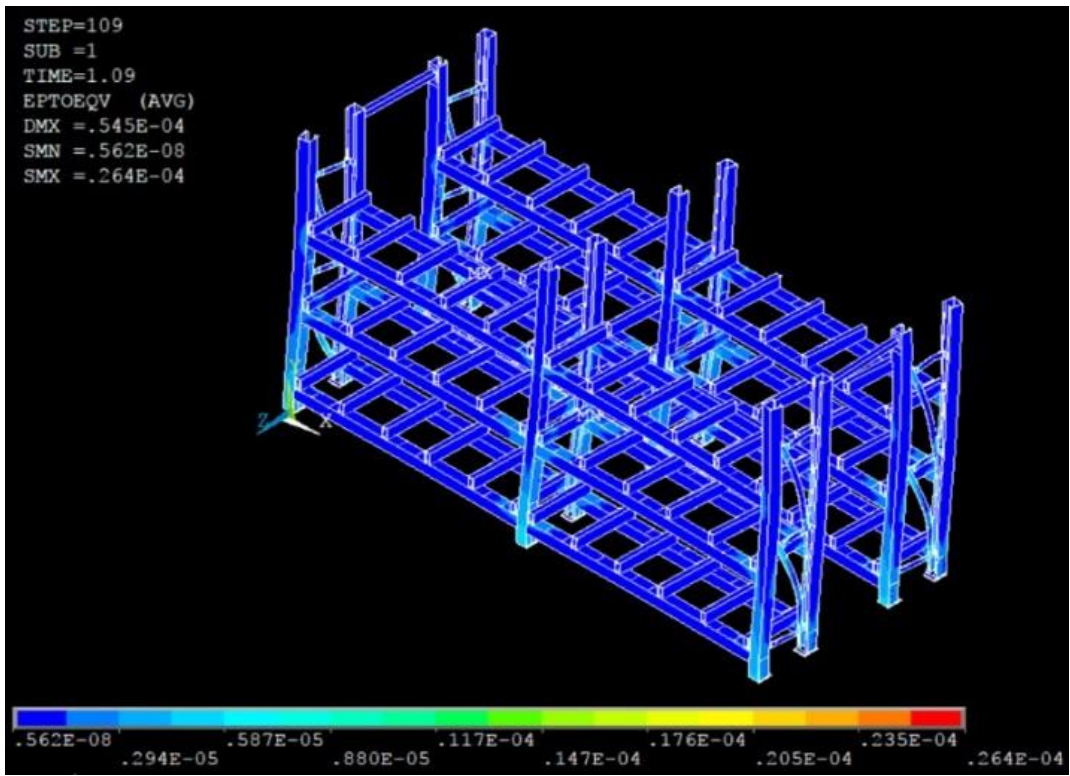

Figure 7. Z-axis storage shelves strain 
As shown in Fig. 8, the shelves in the $\mathrm{X}$ axis 1.09 seconds when the earthquake simulation stress diagram, observation of this Fig. 8 can be found, the shelf stress are concentrated in the column, and the greater the bottom of the larger stress, the maximum value of $861595 \mathrm{~Pa}$. The stress value of the beam at the junction with the column is $383103 \mathrm{~Pa}$. The minimum value of the overall shelf stress is 309.569 Pa.

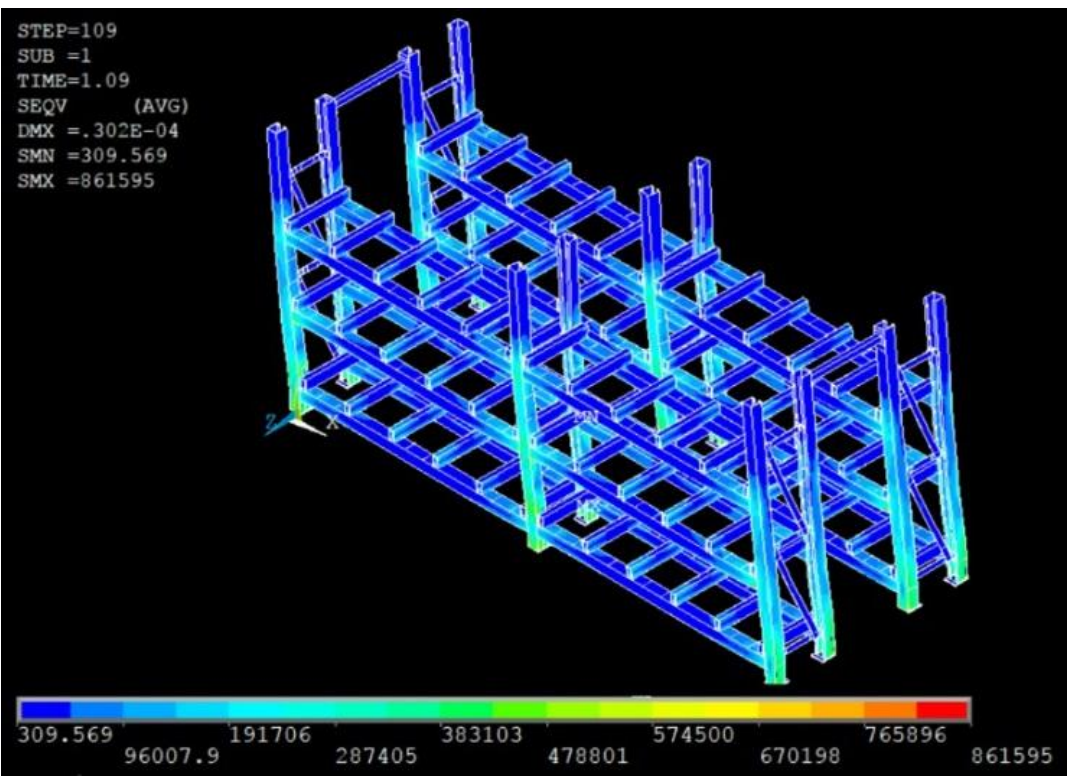

Figure 8. X-axis storage shelves stress

As shown in Fig. 9, the shelves in the Z-axis 1.09 seconds when the earthquake simulation stress diagram, observation of this Fig. 9 can be found, the shelf stress are concentrated in the column, and the more the bottom of the larger stress, the maximum value of $0.528 \mathrm{E}+07 \mathrm{~Pa}$. The stress value of the beam at the junction with the column is $586.930 \mathrm{~Pa}, \mathrm{Z}$-axis column between the rods also have stress occurred, the closer the bottom of the rod stress is greater, the overall shelf stress value of the minimum value of $625.499 \mathrm{~Pa}$.

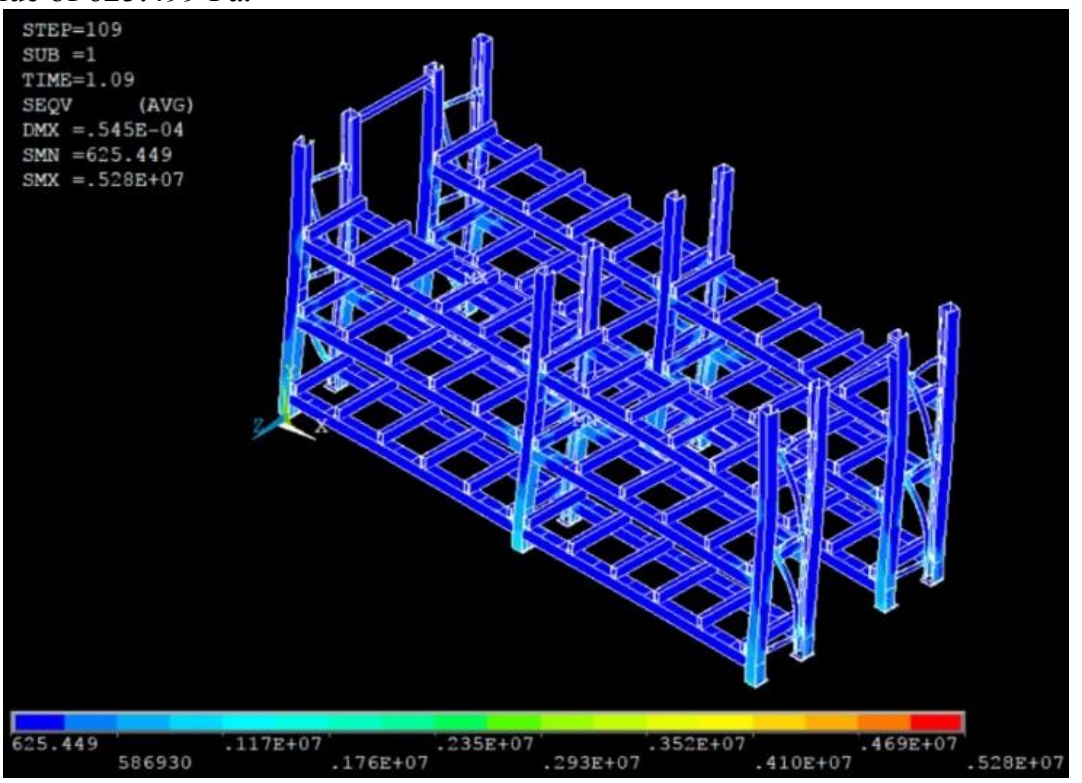

Figure 9. Z-axis storage shelves stress 


\section{Conclusion}

This study used Inventor graphics software to model the shelf, the model into the Workbench for meshing and conditional constraints, then the completion of the model into ANSYS waiting for the solution. In earthquake conditions, in this study a scale 6-level seismic data is taken from the network PEER seismic database system. It can be seen that when the earthquake occurred. Shelf stress and strain are concentrated in the junction of the column and beam. If you want to increase the strength of the shelves to withstand the earthquake, it can strengthen the junction. In order to it improved the higher height, the greater shelf deformation problem. If necessary, consider increasing the fixed condition.

\section{References}

1. J.P. Van Den Berg, A.J.R.M. Gademann, International Journal of Production Research, Simulation study of an automated storage/retrieval system, 38, 1339-1356, 6 (2000).

2. K.J. Vis Roodbergen, F.A. Iris, European journal of operational research, A survey of literature on automated storage and retrieval systems, 194, 343-362, 2(2009).

3. J.C. Wang, J.F. Chai, C.H. Lin, Z.Y. Lin, C.M. Chang, S. Chang, Journal of Architecture, The shockproof study for automation stocker system and high-raised floor, 89, 177-193, (2000).

4. H. Zhao, Y. Ding, X.Y. Wang, S.L. Sheng, Journal of Taizhou Polytechnic College, FEA on stub columns of new steel storage racking, 3 , 70-72, (2012).

5. J.Q. Liu, C.H. Chue, Engineering Applications of Finite Element Analysis with ANSYS (Taichung, Taiwan: Tsang Hai Publishing, 2006).

6. X. Zhang, X. Zhao, Electric Technology and Civil Engineering, Numerical analysis of seismic performance of frame structure with semi-rigid connections, 5216-5218, (2011).

7. A. Şahin, International Congress on Advances in Civil Engineering, ANSeismic - A simple assistant computer program for implementing earthquake analysis of structures with ANSYS and SAP2000, 9, 27-30, (2010).

8. X. Weng, G.Q. Cheng, Q.F. Gao, Hoisting and Conveying machinery, Finite element analysis of special rack structure, 6, 36-38, (2004). 